\title{
Rapidly updated hyperspectral sounding and imaging data for severe storm prediction
}

Gail Bingham, Scott Jensen, John Elwell, Joel Cardon, David Crain, et al.

Gail Bingham, Scott Jensen, John Elwell, Joel Cardon, David Crain, HungLung (Allen) Huang, William L. Smith, Hank E. Revercomb, Ronald J. Huppi, "Rapidly updated hyperspectral sounding and imaging data for severe storm prediction," Proc. SPIE 8867, Infrared Remote Sensing and Instrumentation XXI, 886702 (19 September 2013); doi: 10.1117/12.2030687

SPIE Event: SPIE Optical Engineering + Applications, 2013, San Diego, California, United States 


\title{
Rapidly updated hyperspectra sounding and imaging data for severe storm prediction
}

\author{
Gail Bingham*a , Scott Jensen ${ }^{\mathrm{b}}$, John Elwell ${ }^{\mathrm{b}}$, Joel Cardon ${ }^{\mathrm{b}}$, David Crain ${ }^{\mathrm{c}}$, Hung-Lung (Allen) Huang ${ }^{\mathrm{d}}$,
} William L. Smith ${ }^{\mathrm{d}}$, Hank E. Revercomb ${ }^{\mathrm{e}}$, Ronald J. Huppi ${ }^{\mathrm{f}}$

${ }^{a}$ Space Dynamics Laboratory, 1695 N. Research Park Way, N. Logan, UT; 84341, ${ }^{\mathrm{b}}$ Advanced Weather Systems Foundation, Utah State University, 570 N. Research Park Way, N. Logan, UT; 84341, ${ }^{\text {c }}$

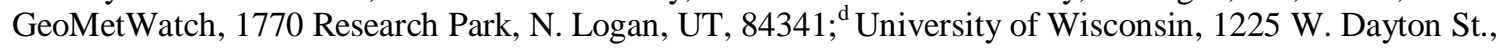
Madison, WI, 53706 and Hampton University, 100 E. Queen St., Hampton VA, 23668, and ${ }^{\mathrm{e} S S E C}$, University of Wisconsin, 1225 W. Dayton St., Madison, WI, 53706, ${ }^{\mathrm{f}}$ Ronald J. Huppi, Sole Proprietor 6 Fairlane Terrace, Winchester, MA 01890

\begin{abstract}
Several studies have shown that a geostationary hyperspectral imager/sounder can provide the most significant value increase in short term, regional numerical prediction weather models over a range of other options. In 1998, the Geostationary Imaging Fourier Transform Spectrometer (GIFTS) proposal was selected by NASA as the New Millennium Earth Observation 3 program over several other geostationary instrument development proposals. After the EO3 GIFTS flight demonstration program was changed to an Engineering Development Unit (EDU) due to funding limitations by one of the partners, the EDU was subjected to flight-like thermal vacuum calibration and testing and successfully validated the breakthrough technologies needed to make a successful observatory. After several government stops and starts, only EUMETSAT's Meteosat Third Generation (MTG-S) sounder is in operational development.
\end{abstract}

Recently, a commercial partnership has been formed to fill the significant data gap. AsiaSat has partnered with GeoMetWatch (GMW) ${ }^{1}$ to fund the development and launch of the Sounding and Tracking Observatory for Regional Meteorology $\left(\mathrm{STORM}_{\mathrm{TM}}\right)$ sensor, a derivative of the Geosynchronous Imaging Fourier Transform Spectrometer (GIFTS) EDU that was designed, built, and tested by Utah State University (USU). STORM $\mathrm{TM}_{\mathrm{TM}}$ combines advanced technologies to observe surface thermal properties, atmospheric weather, and chemistry variables in four dimensions to provide high vertical resolution temperature and moisture sounding information, with the fourth dimension (time) provided by the geosynchronous satellite platform ability to measure a location as often as desired. $\mathrm{STORM}_{\mathrm{TM}}$ will enhance the polar orbiting imaging and sounding measurements by providing: (1) a direct measure of moisture flux and altitude-resolved water vapor and cloud tracer winds throughout the troposphere, (2) an observation of the time varying atmospheric thermodynamics associated with storm system development, and (3) the transport of tropospheric pollutant gases.

The AsiaSat/GMW partnership will host the first STORM $_{\mathrm{TM}}$ sensor on their AsiaSat 9 telecommunications satellite at $122 \mathrm{E}$ over the Asia Pacific area. GMW's business plan is to sell the unique STORM data and data products to countries and companies in the satellite coverage area. GMW plans to place $6 \mathrm{STORM}_{\mathrm{TM}}$ sensors on geostationary telecommunications satellites to provide global hyperspectral sounding and imaging data. Utah State University's Advanced Weather Systems Laboratory (AWS) will build the sensors for GMW.

Keywords: Atmospheric sounding, geostationary, ultra-spectral sounder, GIFTS, STORM $\mathrm{TM}_{\mathrm{TM}}$, severe weather, commercial satellite hosting

\section{INTRODUCTION}

The Washington Post ${ }^{2}$ recently published a story stating that the "World Bank is beginning to commit billions of dollars to flood prevention, water management and other projects to help major Asian cities avoid the expected impact of climate change; a dramatic example of how short the horizon has become to alleviate the effects of global warming." The story continues, "Places such as Bangkok, Jakarta, and Ho Chi Minh City are now considered 'hot spots' that will bear the brunt of the impact as sea levels rise, *Gail.Bingham@sdl.usu.edu; phone 1435 757-2931; fax 1435 713-3430; www.spacedynamics.org

Infrared Remote Sensing and Instrumentation XXI, edited by Marija Strojnik Scholl, Gonzalo Páez, Proc. of SPIE Vol. 8867, 886702 · C 2013 SPIE · CCC code: 0277-786X/13/\$18 · doi: 10.1117/12.2030687 
tropical storms become more violent, and rainfall becomes both more sporadic and - in the rainy season more intense." Severe thunderstorms and their associated destructive surface winds, hail, and tornados appear to have increased in intensity and frequency in the last couple of decades ${ }^{3}$. The observed increase has been attributed to the increase in the moisture holding capacity of the atmosphere, as environmental temperatures have increased. Both humans and animals have evolved, a sense of local weather awareness. However, the ability to forecast the development of severe storms, hurricane intensity and their paths required the development of electronic communications and weather satellites that have only been available in the last half century.

Ultra-spectral sounders (USS) in low earth orbit have significantly improved weather forecast accuracy in recent years, and their impact could be significantly improved with reduced revisit times. The impact of the first generation LEO ultra-spectral sounders (USS), the Atmospheric Infrared Sounder (AIRS) on NASA's Aqua spacecraft, the Infrared Atmospheric Sounding Interferometer (IASI) on EUMETSAT's METOP-A \& B and the Crosstrack Infrared Sounder (CrIS) on the NOAA JPSS S-NPP satellite have had a major impact on the accuracy of the world's major forecast center products ${ }^{4}$. The rich spectral structure in the infrared region of the atmosphere was known to provide information on the vertical profiles of water vapor and temperature and atmospheric sounding capability from space and was first demonstrated by the NASA Nimbus 3 satellite launched on April 13, 1969. Nimbus 3 carried both an Infrared Interferometer Spectrometer (IRIS) to measure atmospheric temperature, water vapor, and ozone in the vertical and a Satellite Infrared Spectrophotometer (SIRS) to provide similar temperature readings. Both the grating and interferometer instruments returned measurements of the IR spectra (See Figure 1) that allowed the beginning of observational sounder development ${ }^{5}$. The resolving power $(\lambda / \Delta \lambda)$ of the developing spectrometers has increased in our ability to resolve the vertical structure of the atmosphere temperature and water vapor profiles. Increased spectral resolution increases both the number of weighting functions available ${ }^{6}$, but also increases the signal to noise of the measurement with the number of near redundant channels contributing to the sounding algorithm. A schematic history of this increase in resolving power with time during the satellite era is shown in Figure 2.

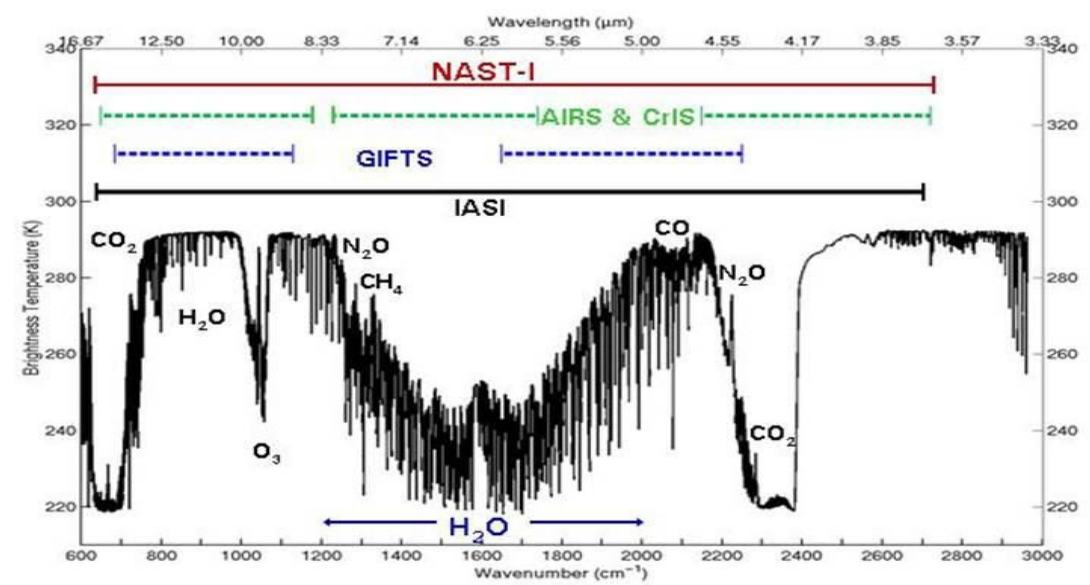

Figure 1. The IR spectra used for atmospheric sounding of the atmosphere and the regions used by some of the current ultra-spectral sounders.

The LEO constellations are spaced to provide the global atmospheric state observations needed to initialize global numerical weather models. They provide excellent coverage for relatively slow moving features. However, for severe weather nowcasting, these data are limited by the spaced crossing times of these valuable assets. To provide rapid updates on storm development, the weather services rely on Geostationary (GEO) observatories. By orbiting over a fixed earth location, they provide the cloud motion pictures that millions observe and interpret during their evening news programs. The imaging and multispectral sounding capability from GEO has evolved significantly since the first weather satellite in that orbit, NASA's Geostationary Applications Technology Satellite demonstrated the ability to see weather systems in motion after its launch in December 1966. The first step toward operational capability was Synchronous Meteorological Satellite (SMS-A), launched in May 1974. SMS-1 (the letter being changed to a number after launch), was a spin-stabilized satellite whose principle instrument was the Visible Infrared Spin Scan Radiometer (VISSR) which provided both day and night imagery of the Earth's surface and 
cloud cover. The NASA SMS series $(1 \& 2)$ were followed by "operational" satellites in the Geostationary Operational Environmental Satellite (GOES) series, beginning with GOES-1 in October 1976. By adding more channels to the VISSR instrument, the VISSR Atmospheric Sounder (VAS) was included in GOES-4, but with limited capability as it had to share access with the imaging system. However the VAS provided the research base ${ }^{7}$ for the later development of a dedicated sounder on the GOES I-M series spacecraft. GOES 8, launched in 1994, provided the first GOES sounder data stream, and being located on a three-axis stabilized spacecraft, could now stare at a location to develop the signal to noise required for more accurate measurements.

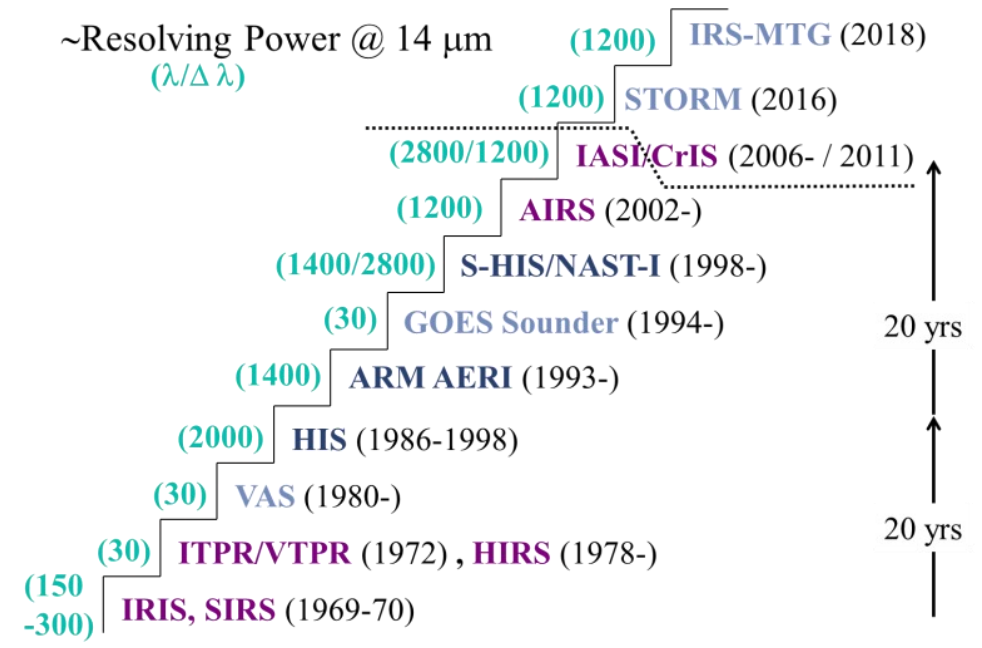

Figure 2. A ladder schematic of the increase in satellite, aircraft, and ground infrared atmospheric sounders since the beginning of the weather satellite era.

The GOES- 8 series sounders were multi-spectral radiometers (18 channels) that observed the radiance with a spectral resolving power (v/dv) of about 100, and therefore had limited vertical resolution (Figure 2). The ultra-spectral sounding requirement developed from the need to obtain higher vertical resolution soundings from the GOES spacecraft to support the production of data that was consistent with the higher horizontal and temporal observations being provided by the imaging system in support of local severe weather forecasting. The first demonstration of this capability came in the form of a series of aircraft instruments. The UW SSEC High-resolution Infrared Sounder (HIS) ${ }^{8}$ first flew on the NASA ER-2 in 1985. An improved (horizontal scanning HIS (S-HIS) and the NPOESS Atmospheric Sounder TestbedInterferometer (NAST-I) ${ }^{9}$ have continued to show that collection of ultra-spectral data from a moving platform is not only feasible, but have been used to validate the first generation of space borne ultraspectral sounders. The Atmospheric Infrared Sounder on NASA's Aqua was the experimental space demonstration of the technique and capability, while the first operational polar orbiting satellite implementation was initiated on the European MetOp-A satellite. The first NOAA ultra-spectral sounder, the Crosstrack Infrared Sounder (CrIS), was launched in 2011 on the Suomi-National Polar Partnership (SNPP) satellite. These sensors provide spectral resolutions from 1000 to 10,000, respectively, providing the additional weighting functions necessary to resolve vertical temperature and water vapor in the 1-2 Km range. High spatial and temporal resolution profiles of water vapor data allow the development of wind profiles that provide another aspect of atmospheric dynamics that are limited in today's databases. With layered wind data, atmospheric chemistry fluxes can be obtained and aircraft routing data more accurate.

\section{THE VALUE OF ULTA-SPECTRAL SOUNDERS}

\subsection{The Advanced Infrared Sounder (AIRS)}

AIRS was launched into Earth-orbit on May 4, 2002, as one of six instruments on board the NASA's Earth Observing System Aqua satellite. AIRS, along with its partner microwave instrument Advanced Microwave Sounding Unit (AMSU-A), represented a significant increase in sounding capability, by increasing the resolving power (Figure 2) of the available sounders in orbit from tens to 2378 channels. Launched as a research instrument, the increase in the available information and its value in weather 
prediction was soon recognized and the AIRS data has been incorporated in numerical forecasts now for nearly a decade. In a 2005 press release, the Joint Center for Satellite Data Assimilation announced "incorporating the instrument's data into numerical weather prediction models improves the accuracy range of experimental six-day Northern Hemisphere weather forecasts by up to six hours, a four-percent increase." ${ }^{4}$ The ability of the higher spectral resolution and AIRS calibration stability have expanded the science to include both global climate and trace gas science as well. A nice picture of the distribution of $\mathrm{CO}_{2}$ in the middle troposphere is available on the JPL-AIRS website. ${ }^{10}$

\subsection{The Infrared Atmospheric Sounding Interferometer (IASI)}

EUMETSAT's IASI was launched on their METOP-A ${ }^{11}$ satellite on October 19, 2006 became the first operational weather sounder. METOP-B continues the significant advancement in weather forecast and climate science work begun by AIRS and expanded by the IASI series. A comparison of the AIRS and IASI sensors and their capabilities is shown in Figure 3.

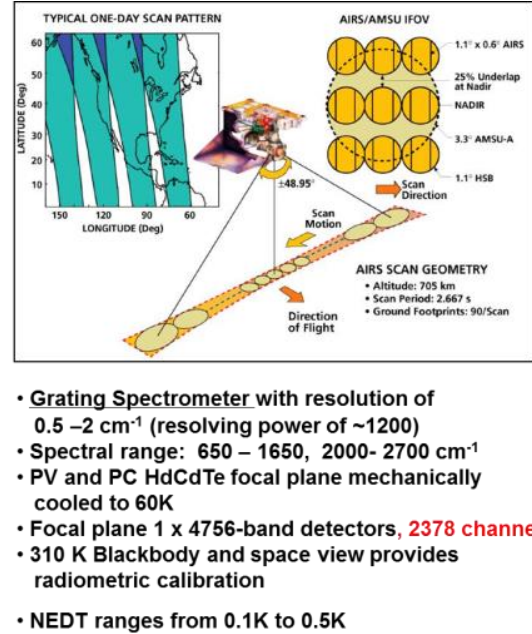

AIRS (2002)

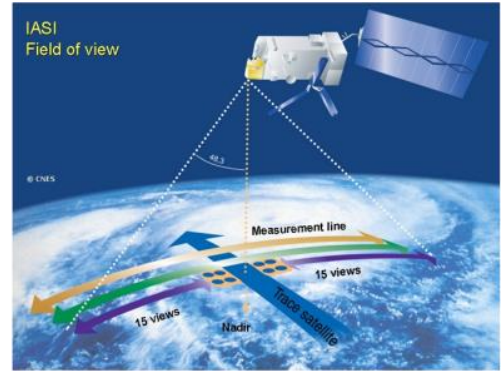

- Michelson Interferometer with resolution of $0.25 \mathrm{~cm}^{-1}$ (resolving power of $2400-12000$ ) - Spectral range: $660-2700 \mathrm{~cm}^{-1}$

- PV and PC HdCdTe focal plane radiatively cooled to $90 \mathrm{~K}$

Focal plane 4 x 3-band detectors, 8461 channels

- $310 \mathrm{~K}$ Blackbody and space view provides radiometric calibration

- NEDT ranges from $0.2 \mathrm{~K}$ to $0.75 \mathrm{~K}$

Figure 3. A schematic diagram comparing the AIRS and IASI scan patterns and their top level technical details.

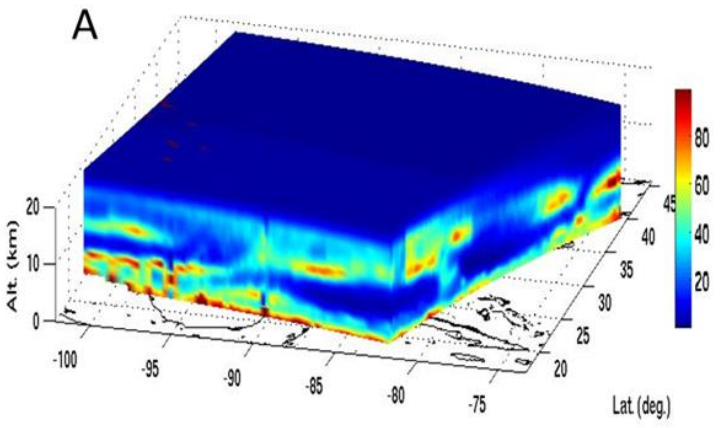

Lon. (deg.)

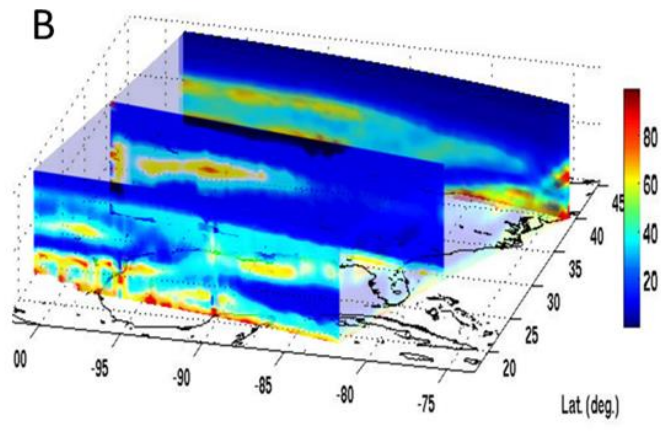

Lon.(deg.)

Figure 4. (A) The 3D image of a block of 100 scans of vertical profiles of water vapor collected by IASI. (B) A breakout of 3 of the horizontal scans in (A) showing some of the variation in structure measured by this pass.

The significance of these ultra-spectral sounders in improving our understanding of atmospheric conditions and dynamics can be seen in Figure 7. The tremendous detail of the troposphere available in this water vapor data is clearly evident. For example, look at the 20d Lat, -87d Long region on the last scan, showing the finger of high moisture concentration in the boundary layer, over lain by the dry air layer above it, a potential trigger for the development of strong thunder storms in that region. Unfortunately, several hours will pass before another ultra-spectral sounder will pass over this region to measure the development of 
instability. Rapid temporal measurements of this region are available from the GEO instruments, but as yet, no hyper or ultra-spectral sounders have been developed to provide this capability.

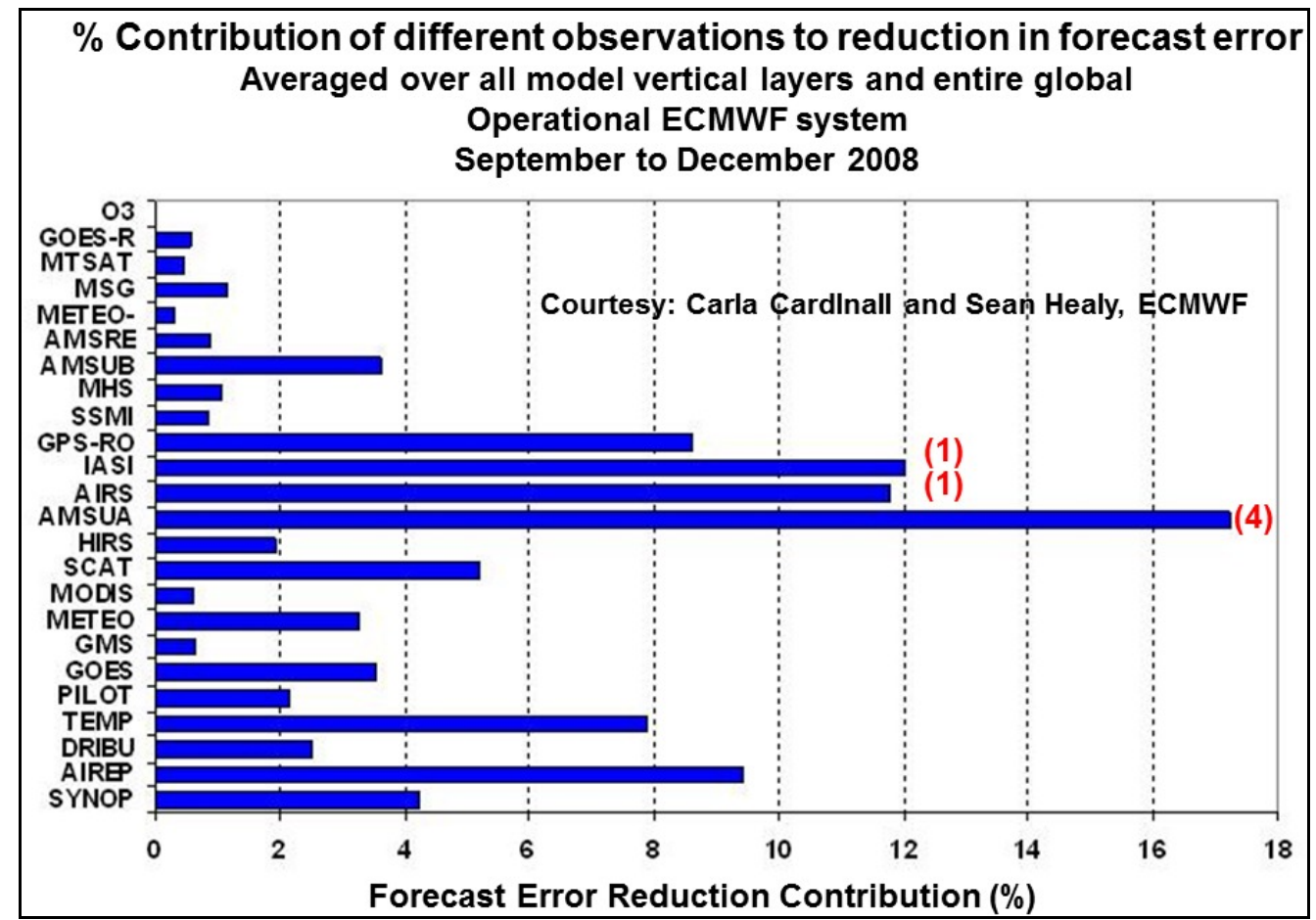

Figure 5. Sensor data contribution to forecast accuracy in the ECMWF system in 2008.

\subsection{The Cross-track Infrared Sounder (CrIS)}

The first U.S. ultra-spectral sounder in operational service is the CrIS sensor, launched on the Suomi National Polar-orbiting Partnership (S-NPP). The Cross-track Infrared Sounder (CrIS) is a Fourier transform spectrometer (FTS) with 1305 spectral channels, which produce similar high-resolution, threedimensional temperature, pressure, and moisture profiles as the AIRS sensor. The Cross-track Infrared Sounder (CrIS), provides soundings of the atmosphere with 1305 spectral channels, over 3 wavelength ranges: LWIR (9.14 - 15.38um); MWIR (5.71 - 8.26um); and SWIR (3.92 - $4.64 \mathrm{um).} \mathrm{The} \mathrm{CrIS} \mathrm{instrument,}$ a Fourier transform spectrometer, has an $8 \mathrm{~cm}$ clear aperture and uses plane mirror interferometer technology. CrIS scans a $2200 \mathrm{~km}$ swath width (+/- 50 degrees), with 30 Earth-scene views. Each field consists of 9 fields of view, arrayed as $3 \times 3$ array of $14 \mathrm{~km}$ diameter spots (nadir spatial resolution). Each scan (with an 8-second repeat interval) includes views of the internal calibration target (warm calibration point), and a deep space view (cold calibration point). The overall instrument data rate is $<1.5 \mathrm{Mbps}$. Only photovoltaic detectors are used in the CrIS instrument. The detectors are cooled to approximately $81 \mathrm{~K}$ using a 4-stage passive cooler with no moving parts. As shown in Figure 1, CrIS and AIRS have the same data collection bands, and currently have similar spectral resolution in each band. However, because CrIS is an FTS system, it collects the same resolution data in all three bands, but discards half of the midwave data and 3/4ths of the short wave data to achieve the reduced spectral resolution. At present, an effort is being conducted to bring full $\left(0.6 \mathrm{~cm}^{-1}\right)$ spectral resolution to the ground for use by the science community. However, the weather processing system will continue to disregard the higher spectral resolution data in the shorter wavelength channels until a significant upgrade of the processing software can be funded.

The profiles developed by these ultra-spectral sounders will continue being used to enhance weather forecasting models, and facilitate both short- and long-term weather forecasting. Over longer timescales, they will also help improve our understanding of climate phenomena such as El Niño, La Niña and global temperature change. 


\section{GEOSTATIONARY ULTRA-SPECTRAL SOUNDER DEVELOPMENT}

\subsection{The recognized need}

In the mid-90's NASA decided that they needed to extend some of their development effort to include sensors in geostationary orbit. From the multiple proposals submitted to the call for the next New Millennium Earth Observing program, the Geostationary Imaging Fourier Transform Spectrometer (GIFTS) was selected. The objective of the Earth Observing 3 (EO3) GIFTS ${ }^{12}$ project was to develop and test the new technologies required to move ultra-spectral sounding from LEO to GEO. The EO3 program identified eight technologies to be matured under the GIFTS program. These included the following:

- A cryogenic Michelson interferometer with a spatial sampling system optimized for imaging

- Large area detector arrays and readouts and associated miniaturized cryocoolers

- High speed, ultra-low-power signal processing

- A radiation-hardened vector processor for onboard real-time signal processing and data compression

- Autonomous pointing and control systems for precise image stabilization and feature tracking

- Radiation protection and ultra-low-power electronics

- Lightweight optics and structures to minimize instrument mass

These technologies would not only benefit the EO3 missions, but also other sensors proposed for earth observation.

\subsection{The GIFTS program}

While originally proposed as a gimbaled, secondary payload on the on NASA's TDRS J satellite, it quickly became obvious that the two programs had serious incompatibilities. By the end of the Phase A study, a new program organization had been developed that involved a dedicated mission support by the US Navy, NOAA and NASA, with the Navy providing both the spacecraft and a launch using the Air Force Space Test Program. Three major challenges faced the GIFTS - IOMI (Indian Ocean METOC Imager) mission, the first being the coordination of objectives and budgets for three agencies. The next two; weight and processing power, were technological and were overcome.

\subsection{LEO to GEO}

Transferring the ultra-spectral technology from LEO to GEO requires two things, a significantly larger data collection system, and increased on-board processing and communications capabilities. A comparison of the LEO CrIS sensor and the soon to be launched Advanced Baseline Imager (ABI) to be flown on the NOAA's GOES-R satellite in 2015 is shown in Figure 7. GIFTS uses a two-axis pointing mirror to stop and stare within +/- 10 degrees of Earth center, allowing it to view the whole Earth and surrounding space. Viewing surrounding space allows for deep space calibration of the entire optical system and star viewing for navigation verification. A flip in mirror provides sun protection for optics and focal planes and provides the two precision blackbody cavities. GIFTS uses a 3 temperature calibration system, the two deep cavity blackbodies and deep space. A dichroic is used to split off the shorter wavelengths not used by the FTS system and provide images of clouds and aerosols via a visible/near IR camera. Six temperature zones were used in the GIFTS optical system to provide stable instrument calibration over the full 360 sun exposure experienced daily by a sensor in GEO orbit. GIFTS was designed for a spacecraft that could execute a yaw flip every 6 months to assure that the passive radiators that controlled optical temperature were always facing away from the sun (see Figure 7). 

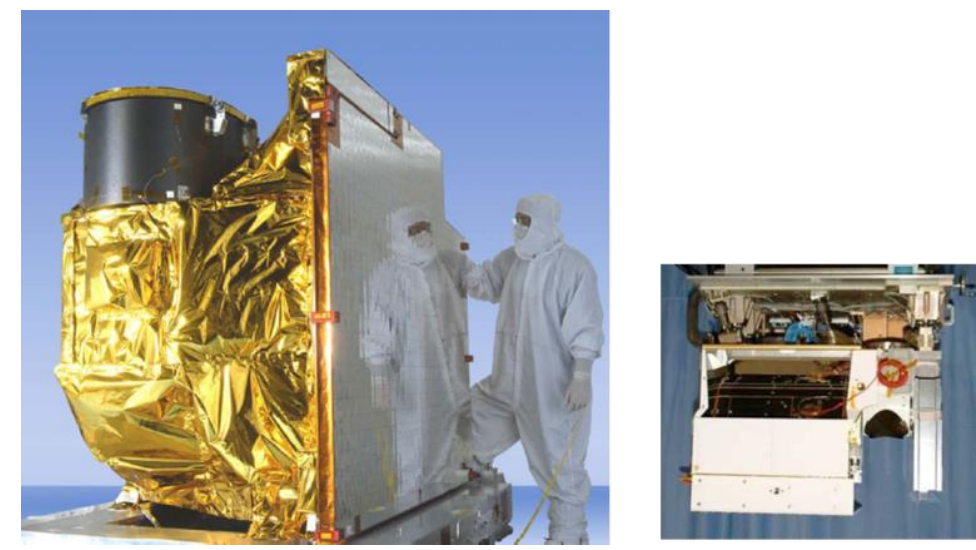

Figure 6. A comparison of the GOES ABI (left) and the S-NPP CrIS sensor (right) size. ABI's optical aperture diameter is almost 10 times that of the $8 \mathrm{~cm}$ aperture on CrIS.

\subsection{GIFTS data system}

GIFTS is a massively parallel FTS system which incorporates two IR 128 x 128 pixel focal planes. Large area format Focal Plane detector Arrays (LFPAs) provide near instantaneous large area coverage with high horizontal resolution. The imaging FTS enables atmospheric radiance spectra to be observed simultaneously for all LFPA detector pixels, thereby providing high vertical resolution temperature and moisture sounding information. Each pixel has an 112ur (4 Km IFOV), giving the GIFTS instrument a square $512 \mathrm{Km}$ field of view at nadir. The full $0.8 \mathrm{~cm}$ interferometer mirror scan requires just less than 11 seconds. Since each pixel images a different spot on the Earth, the instrument collects 16,384 separate interferograms (actually 32768 when both FPAs are considered) in that period. Even when the time required to step the mirror to an adjacent location is considered, GIFTS could collect more than 80,000 atmospheric sounding per minute. With its rapid repeat capability, a GEO ultra-spectral sounder can provide a 4D image of the atmosphere, the fourth dimension (time, being provided by the geosynchronous satellite platform). The capability to stare at a particular feature enables near continuous imaging of the atmosphere's three-dimensional structure. The state of the art for LFPAs in the year 2000 required significant additional development and the GIFTS units were not perfect.

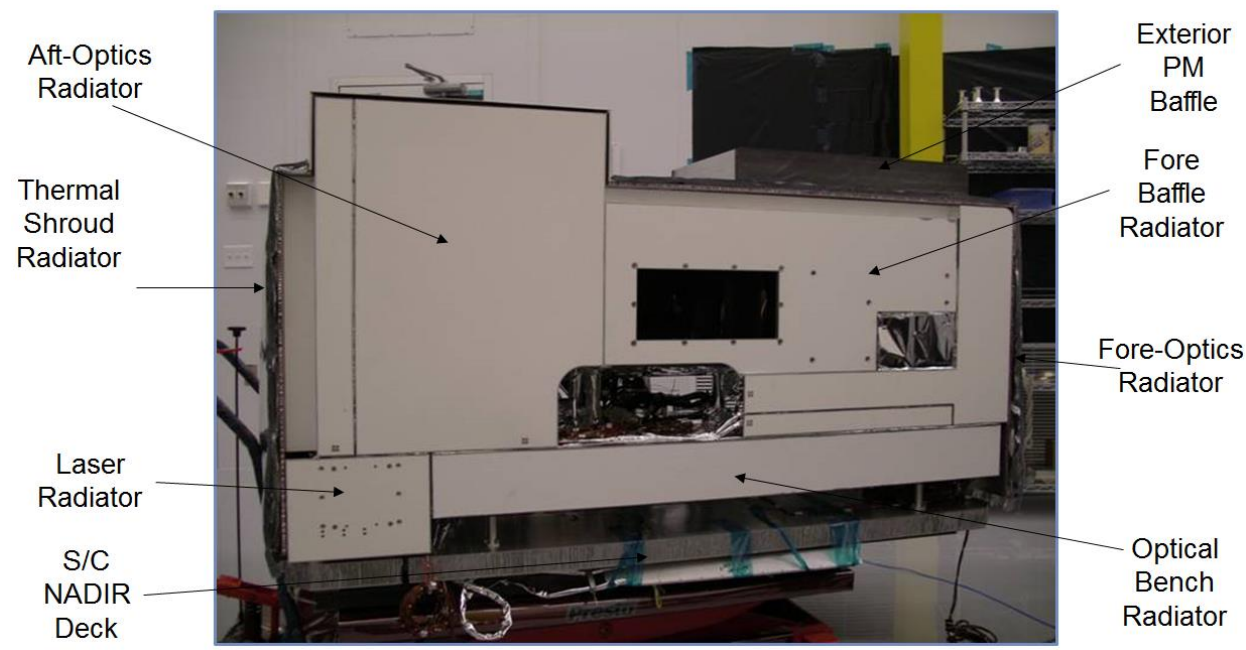

Figure 7. The radiator panels on the anti-sun side of the GIFTS sensor.

The second significant challenge in the GIFTS design was the data collection and processing system. The design of the data collection and processing system is shown in Figure 5. The LFPAs had 20 high-speed analog data outputs that were digitized at 14 bits and co-added to 16 bit resolution. The 32,384 interferograms (113 Mpixels/sec) were fed to a digital signal processor, which filtered and down sampled 
the LFPA data stream to a manageable $135 \mathrm{Mb} / \mathrm{sec}$. A single frame from the 512 x 512 pixel visible/NIR camera for each IR scan was added to the data stream by the command and data handling system.

\subsection{Performance testing and demonstration}

While all of the GIFTS major components were ordered as flight hardware, near the middle of the assembly it was discovered that the Navy had eliminated funding for the spacecraft and in quick succession, the Air Force canceled the launch vehicle. NASA was left with the choice to finish the unit as a non-flight Engineering Demonstration Unit (EDU) or to cancel it outright. GIFTS was completed as an EDU, completed a full thermal vacuum calibration cycle, and some significant external atmosphere measurements. The GIFTS EDU met all of its radiometric performance requirements.

NASA also funded a series of external measurements to demonstrate the maturity of their newly developed technologies. A large ZnSe window was installed on the GIFTS thermal vacuum chamber that allowed the sensor aperture to view a roll up door in the calibration laboratory (see Figure 9).

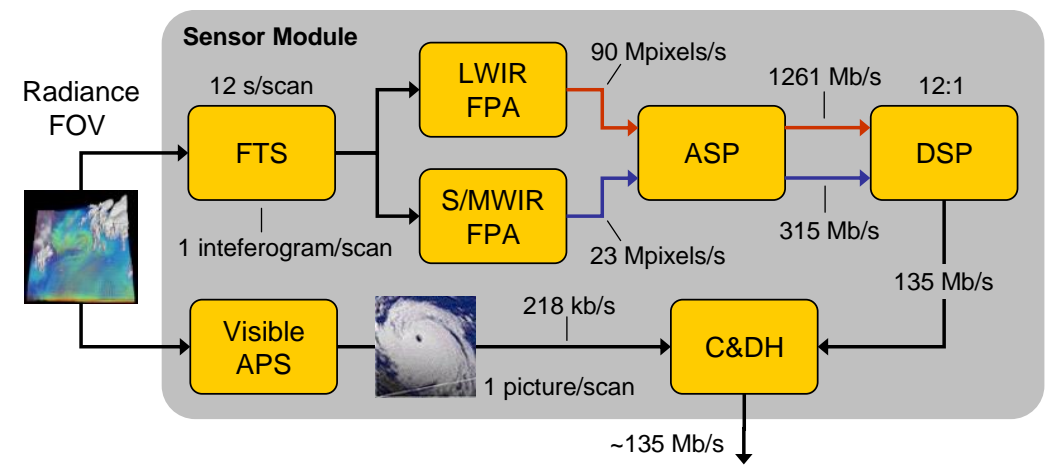

Figure 8. A schematic diagram of the GIFTS data collection and processing system.

Three sets of external measurements were made: a moon tracking experiment, a six hour series of uplooking atmospheric soundings, and a horizontal mountain scene measurement. ${ }^{13}$ The Atmospheric Emitted Radiance Interferometer ${ }^{14}$ (AERI) instrument was designed and fabricated by the University of Wisconsin Space Science and Engineering Center (UW-SSEC) for the Department of Energy (DOE) Atmospheric Radiation Measurement (ARM) Program as an up-looking radiance reference. Spectra collected by the individual GIFTS pixels and AERI instrument were identical ${ }^{6}$ to within the instrument noise level (see Figure 10).
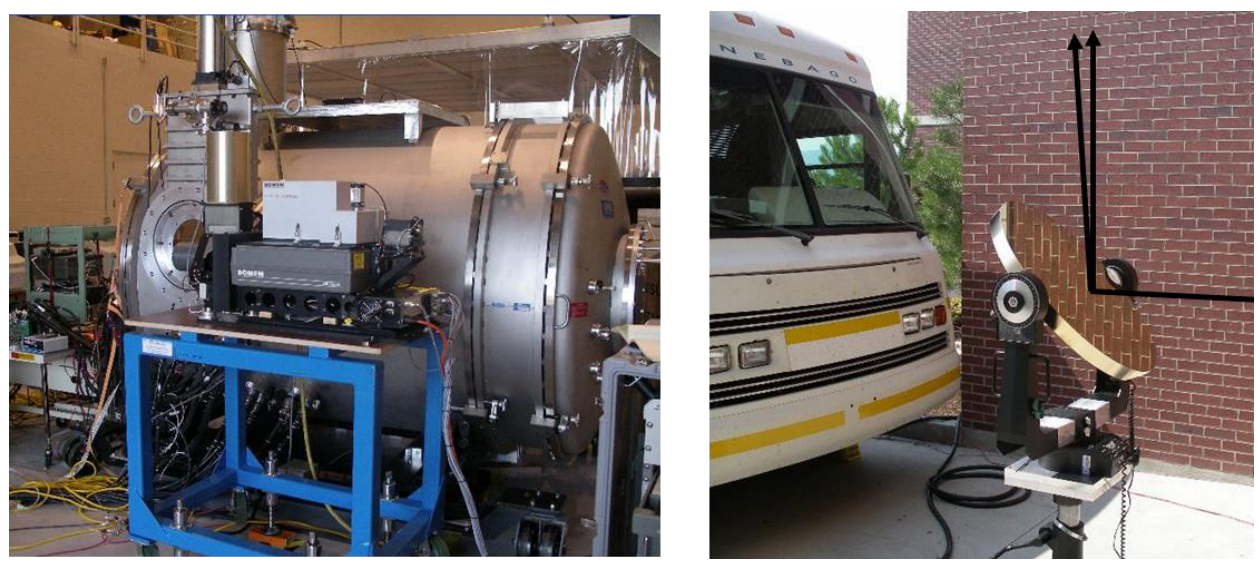

Figure 9. (Left) The GIFTS thermal vacuum chamber with the window to allow viewing the outside environment. The UW AERI is located on the table near the chamber to provide a comparison measurement for the GIFTS data.

(Right) Both systems view a large turning mirror outside the building to make vertical profile measurements.

The imaging capability of the GIFTS EDU was demonstrated by capturing images and spectra from the passing moon. Figure 11 shows images from the 3 GIFTS LFPAs, the LW on the left, the visible in the middle, and the S/MW on the right. The IR images are from a single wavenumber bin in an atmospheric 
window region. Spectra for each of the IR pass bands are shown below the moon images, with arrows pointing to the region pixel from which the spectra were developed.

(a) Accurate radiances obtained from GIFTS EDU

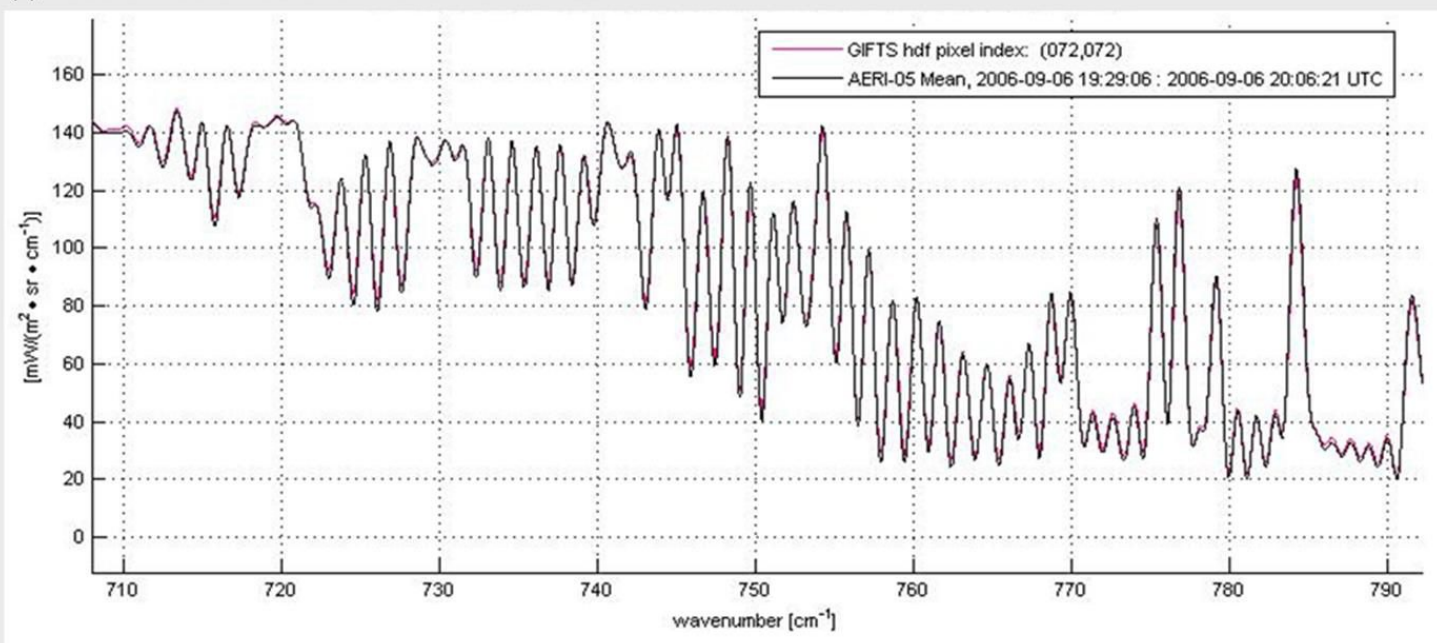

Figure 10. Atmospheric radiance spectra made by GIFTS (pixel 072,072) and the AERI 5.
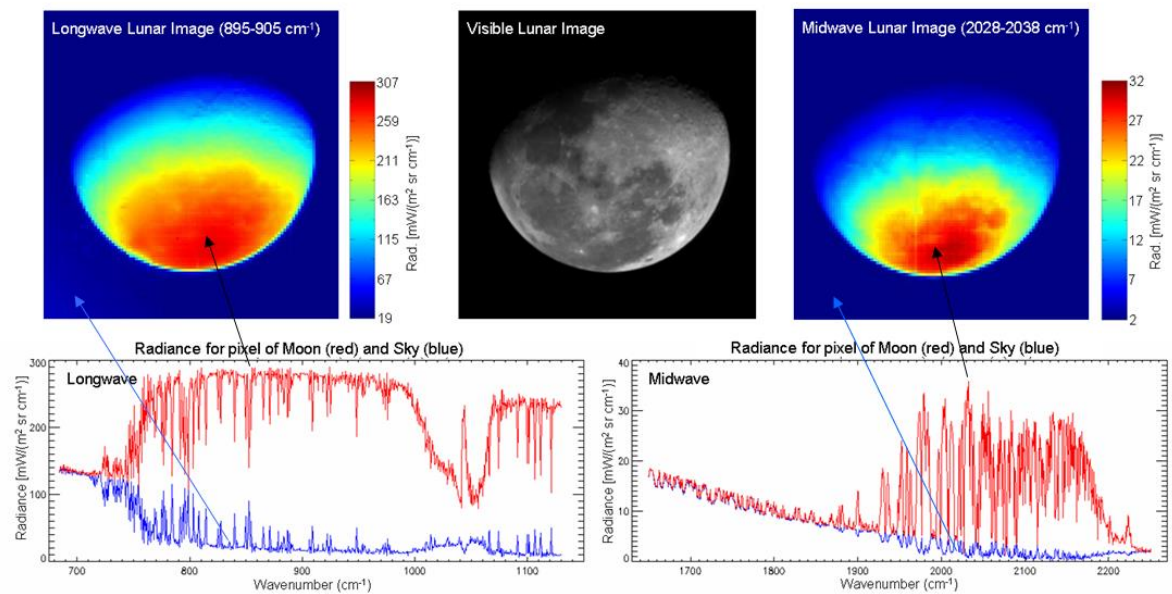

Figure 11. Images of the moon captured by a single interferometer scan of the GIFTS EDU, with single pixel spectra from the moon surface and the deep space around the moon. Note the atmospheric structure in the space view.

After the test program was completed, the GIFTS EDU was mothballed and stored at SDL until 2012, when it was shipped to the NASA Langley Research Center for continued storage.

\subsection{Another start, another stop}

Having successfully matured the selected EO3 technologies, GIFTS was provided to NOAA as the base technology for the Hyperspectral Environmental Suite (HES) for the GOES R procurement. After several options were explored, requirements expanded, and three Phase A studies completed, the HES option was dropped for financial reasons. A major contributor to the decision was the cost of the certified ground processing system to handle the flood of data that HES would have provided. 


\section{REVIVING GIFTS TECHNOLOGY}

The GIFTS team spent the next several years looking around the world for government support to complete and launch the GIFTS ultra-spectral sounder and demonstrate its tremendous value in saving lives and property. It eventually became obvious that a new approach was required to realize this goal.

\subsection{The commercial funding model}

A startup company was formed to secure commercial funding for instrument development, with the concept to eliminate the launch cost by entering a revenue sharing agreement with a commercial communications satellite operator. GeoMetWatch (GMW) ${ }^{1}$ was founded in 2008 and is registered in Nevada. On September 15, 2010, GMW was granted the first commercial remote sensing license from the US Department of Commerce to receive and sell atmospheric data collected from geosynchronous orbit. GMW formed a strategic partnership with Utah State University (USU) in 2010 to upgrade the GIFTS design to become their sensor solution. In 2011, GMW began working earnestly with satellite service providers and satellite bus providers throughout the world to establish a presence and to look for a hosting partner. In 2013 this effort had a successful conclusion when the Asia Satellite Telecommunications Company Limited (AsiaSat) and GMW Corp announced that the two companies had entered into a strategic partnership to host the first of six Sounding and Tracking Observatory for Regional Meteorology (STORM $\left.\mathrm{TM}_{\mathrm{T}}\right)$ instruments onboard a new satellite planned to be launched by AsiaSat in 2016. The latest step in this ongoing effort occurred recently, when NASA and GMW signed a Space Act Agreement to return the GIFTS sensor to Utah to provide a testbed for the new STORM $_{\mathrm{TM}}$ components.

\subsection{Formation of the Advanced Weather Systems foundation}

GIFTS was developed by the Utah State University Research Foundation's Space Dynamics Laboratory (SDL), which is also a US Department of Defense University Affiliated Research Center. To avoid conflict with that role, USU established a new foundation, the Advanced Weather Systems foundation (AWS) to handle commercial contracts, including the GMW STORM $\mathrm{TM}_{\mathrm{TM}}$ program. AWS is a wholly owned and controlled, not-for-profit foundation under USU. Several of the key SDL GIFTS team members transferred to AWS to push the STORM program forward. As a strategic partner of GMW, AWS is currently participating with the other GMW partners to bring the STORM sensor to reality.

\subsection{STORM from GIFTS}

While GMW presentations often present the "capability" that can be provided by a STORM sensor, the first instrument $\left(\mathrm{STORM}_{\mathrm{TM}}-1\right)$ is proposed as having the same capability as the original GIFTS sensor, wherever possible. The purpose of this limitation is to minimize risk and shorten development time to a minimum. Because of challenges in finalizing total program funding, making a late 2016 launch date will be a challenge, despite the team having built this sensor before. The primary schedule drivers in STORM $_{\mathrm{TM}}$ -1 fabrication are the long lead items and the redesign of the electronics using modern electronic parts.

The specifications for STORM $\mathrm{TM}_{\mathrm{TM}}-1$, as compared to GIFTS are shown in Table 1. The band pass regions AWS has proposed to GMW are the same, to eliminate the need to design new filters and optics. Spectral resolution options have been reduced from 7 to 3 to reduce testing \& calibration time. Lower resolutions can be achieved by truncating the interferogram, but collecting a shorter interferogram does not save sample time as the limit becomes the time required to collect and save the visible image during each scan. System FOV and FOR remain the same, providing $4 \mathrm{Km}$ footprints and a $512 \mathrm{Km}$ image with the IR cameras. The NESR specifications have not changed, but were exceeded by GIFTS and are expected to be

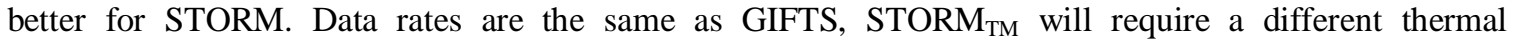
management system since the use of a yaw flip will not be available on the communications satellite. In addition, $\mathrm{STORM}_{\mathrm{TM}}-1$ will be fully redundant to allow the sensor to meet the 15 -year lifetime of the host satellite. 
Table 1. Specification comparison between the GIFTS EDU and STORM $\mathrm{SM}_{\mathrm{TM}}-1$.

\begin{tabular}{|c|c|c|}
\hline Parameter & GIFTS & STORM $_{\mathrm{TM}}$ \\
\hline Spectral bands & $\begin{array}{l}\text { LW: } \leq 685 \mathrm{~cm}^{-1} \text { to } \geq 1130 \mathrm{~cm}^{-1} \\
\text { SMW: } \leq 1650 \mathrm{~cm}^{-1} \text { to } \geq 2250 \mathrm{~cm}^{-1} \\
\text { VIS: } \geq 0.725 \mu \mathrm{m} \text { to } \leq 0.875 \mu \mathrm{m}\end{array}$ & Same \\
\hline Spectral resolution & 7 resolutions in range $0.6-36.7 \mathrm{~cm}^{-1}$ & $0.6,1.2$, and $9.6 \mathrm{~cm}^{-1}$ \\
\hline FPA field-of-view (FOV) & $14.3 \operatorname{mrad}\left(0.82^{\circ}\right)$ & Same \\
\hline Field-of-regard (FOR) & $\begin{array}{l}\geq 0.306 \mathrm{rad}\left(17.53^{\circ}\right) \\
\text { (pointing mirror design: } 0.450 \mathrm{rad} \text { ) }\end{array}$ & Same \\
\hline IR FPA format & $128 \times 128$ pixels, $60 \mu \mathrm{m}$ pixel pitch & Same \\
\hline $\begin{array}{l}\text { Noise equivalent spectral } \\
\text { radiance (NESR) goal }\end{array}$ & $\begin{array}{l}\mathrm{LW}: \leq 0.4 \mathrm{~mW} /\left(\mathrm{m}^{2}-\mathrm{sr}^{-\mathrm{cm}^{-1}}\right) \\
\mathrm{SMW}: \leq 0.06 \mathrm{~mW} /\left(\mathrm{m}^{2}-\mathrm{sr}^{\left.-\mathrm{cm}^{-1}\right)}\right.\end{array}$ & Same \\
\hline Calibration accuracy goal & $\leq 1 \mathrm{~K}(3 \sigma)$ & Same \\
\hline Data rate & $\begin{array}{l}\text { Max: } 70-80 \mathrm{Mb} / \mathrm{sec} \\
\text { Nom: } 58-73 \mathrm{Mb} / \mathrm{sec}\end{array}$ & Same \\
\hline
\end{tabular}

\section{GEOSTATIONARY ULTRA-SPECTRAL SOUNDER PAYOFF}

$\mathrm{STORM}_{\mathrm{TM}}-1$, on AsiaSat 9 will be located at $122 \mathrm{E}$ longitude, over the high population density of the Asian continent, and a region often impacted by severe thunderstorms, flooding, and tropical cyclones. The extra capability to rapid refresh of imaging and sounding data is extremely valuable in this region. When GMW's goal to provide six, uniformly-spaced systems in GEO orbit, they will provide this added value to more than $70 \%$ of the earth's population. Some of these benefits include:

\section{Water vapor wind profiles}

Water vapor in the atmosphere appears relatively smooth, when viewed by our sparse weather balloon or large footprint atmospheric sounders (while CrIS has a $14 \mathrm{Km}$ footprint, retrievals are currently only produced on a $50 \mathrm{Km}$ grid). However, the puffy summer cumulus that occur indicate that moisture variability at high frequency must be much greater than the general trend used in our forecast models. To demonstrate this variability, a 1998 experiment was performed using the NASA ER-2 and the NAST-I sounder. The ER-2 flew racetrack loops to provide repeated observations of the same $40 \times 60 \mathrm{Km}$ region. Water vapor retrieval images of the area show $4-10 \mathrm{Km}$ uncondensed structures moving with the wind. The structures differ with each sounding level, while comparison with radiosondes in the same region show the vapor derived winds agreed with the sonde-derived winds to about $4 \mathrm{~m} / \mathrm{s}$. A simulation of the water vapor structure that could be seen with a $3 \times 3$ GIFTS sounding cube is shown in a UW-CIMSS simulation in Figure 12. These winds are not only valuable for storm prediction, but would be extremely valuable for aircraft management and routing. Wind speed accuracy is dependent primarily on relative sensor repointing knowledge and is estimated for $\mathrm{STORM}_{\mathrm{TM}}$ to be $2-3 \mathrm{~m} / \mathrm{s}$.

\section{Instability (severe convection) prediction}

The availability of high spatial $(4 \mathrm{Km})$, high temporal ( 30 minutes) temperature and water vapor profile information provide the basis for accurate forecasts of severe storm development hours before the storm cells appear on radar. Since about between $70-85 \%$ of our tornado warnings are false alarms, they are often ignored, until the hook echo appears on the radar and that appears on the TV. By that time, it is too late to avoid the life threatening damage. Figure 4 shows the capability of the ultra-spectral sounder to see the low level tongue of warm moist air siding in under a cool dry air layer aloft, the primer for a severe storm when the heating of the day is included. This warning is available long before the clouds begin to form. Knowing the distribution of the water vapor, the winds, and water vapor movement, increases the ability to predict rainfall intensity and volume, also improving flood forecasting. 


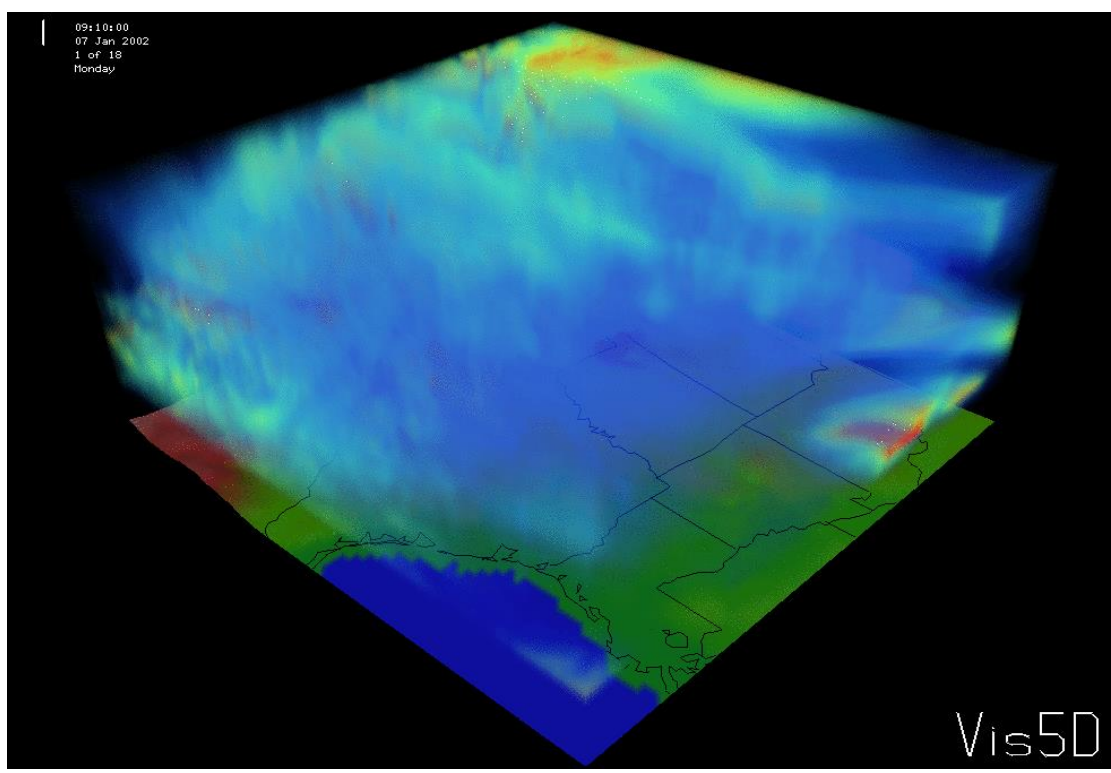

Figure 12. Movement of uncondensed water vapor structure layers provides wind vectors using the same software used for cloud motion winds.

\section{Smaller footprint size}

Numerical Weather Prediction codes are grid based, with data required to initialize each grid point at the beginning of the run. Figure 14 illustrates the progressing decrease in grid size in the ECMWF model between 1981 and 2012. It also shows the increased accuracy of the forecasts over that period. What is implied, but not shown, is the required data spatial resolution required to initialize the model. Currently, the time step in the ECMWF NWP model is 10 minutes. Predicted into the future, the resolution elements decrease to $10 \mathrm{Km}$ and 7.5 minutes in 2015/16 and 5Km and 4 minutes in 2020. Currently available sensors cannot meet these data needs. This continued trend also implies vast increases in the associate computer power required to do these calculations.

One of the significant benefits of the STORM $\mathrm{TM}_{\mathrm{TM}}$ style imaging ultra-spectral sounder for compute strapped customers is its massively parallel feature. Because the interferogram captured by each pixel is independent of the ones adjacent, computing load can be scaled with need by simply processing only the pixels required (a feature currently also used in CrIS and IASI processing). For added accuracy with a small increase in computer resources, adjacent interferograms can be co-added (to improve signal to noise) at the cost of spatial resolution, but valuable sensitivity for low frequency variables such as $\mathrm{CO}_{2}$.

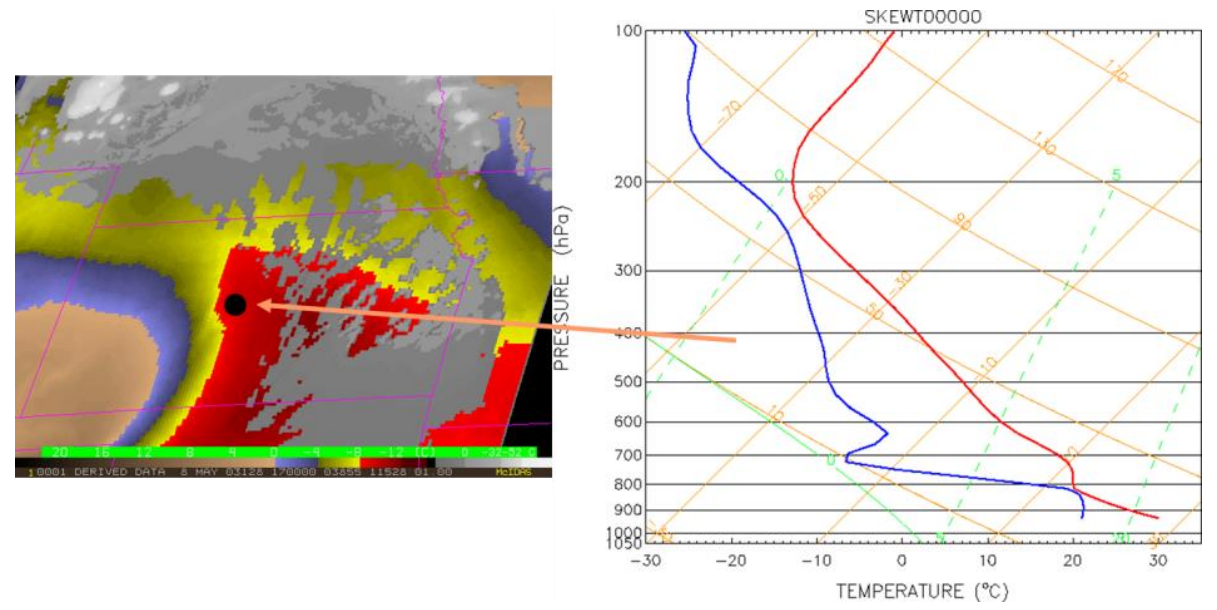

Figure 13. Semi-continuous vertically resolved temperature and water vapor profiles capture the fast evolving serve weather life cycle that provides the only chance for storm warning and precision forecast. In the images above, red represents extreme instability. 


\section{Evolution of ECMWF forecast skill}

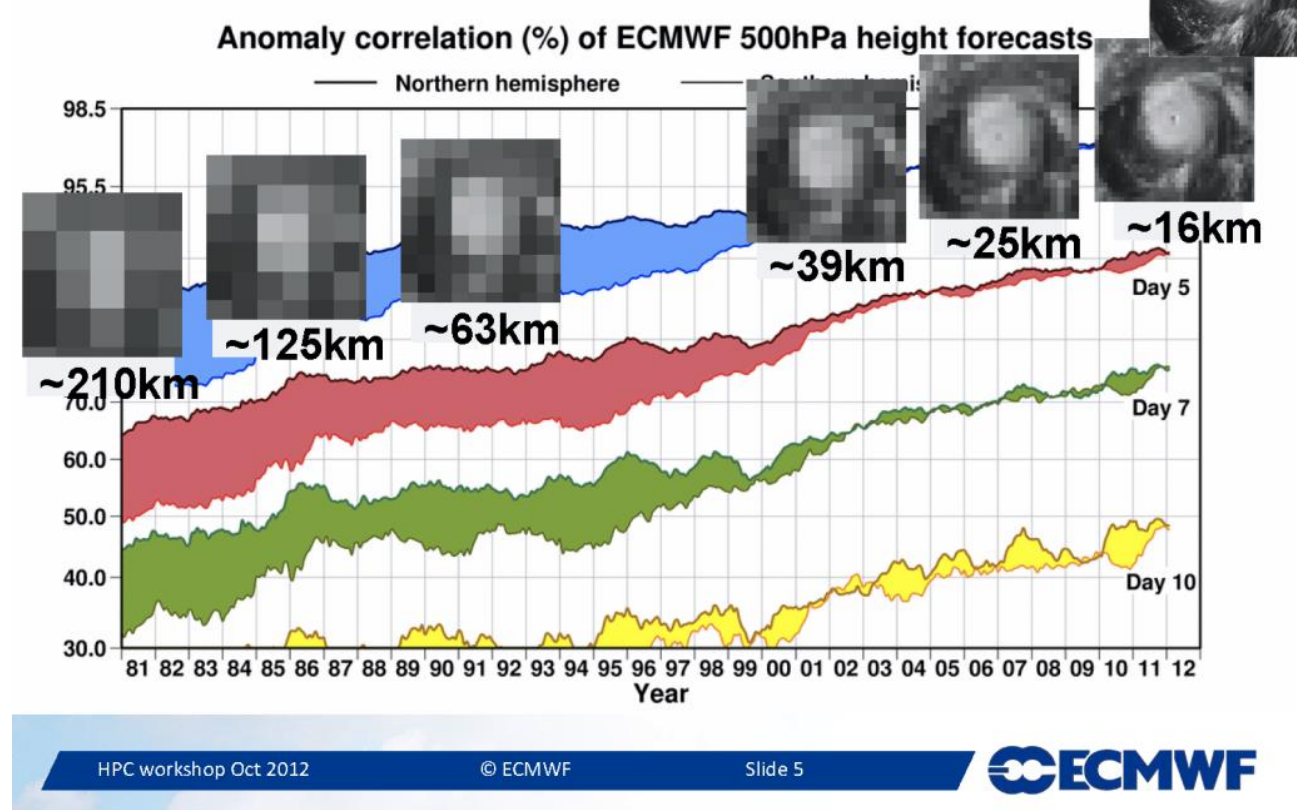

Figure 14. A slide from the ECMWF HPC workshop in 2012 illustrates the progressive decrease in model grid size with time, and the corresponding forecast accuracy that accompanied the reduction.

\section{SUMMARY}

We have attempted to show the significant value of having ultra-spectral sounders, such as STORM $_{\mathrm{TM}}$ in geostationary orbit. While the value of ultra-spectral data have been demonstrated in the LEO orbit, their repeat time does not allow for the full benefit that can be achieved by quicker revisits, in the order of minutes. The next GOES imager, ABI, provides new capability, but cannot provide the high vertical resolution of the $\mathrm{STORM}_{\mathrm{TM}}$-style sensors. A new approach to weather data collection and delivery has been initiated by GMW in an attempt to secure ultra-spectral weather and atmospheric state data from GEO orbit. GMW's three strategic partners, the Advanced Weather Systems Foundation at Utah State University, the Space Science and Engineering Center at the University of Wisconsin - Madison, and the Asia Satellite Telecommunications Company Limited are committed to bring this valuable data to government and commercial customers under AsiaSat 9 at $122 \mathrm{E}$ in late 2016. The GIFTS team, including our NASA sponsor are anxious to see this next advance in earth observation come to fruition after more than a decade of effort. If GMW is successful in developing its full constellation of six regularly spaced GEO satellites, it will provide data of unprecedented value to people around the world living in the latitude band from 60 degrees north and south of the equator, protecting the lives of more than $70 \%$ of the world's population. 


\section{REFERENCES}

[1.] GeoMetWatch, Inc. 1770 North Research Park Way, North Logan, UT 84341. http:/geometwatch.com/

[2.] http://www.washingtonpost.com/ on June 19, 2013

[3.] Robert J. Trapp, Noah S. Diffenbaugh, Harold E. Brooks , Michael E. Baldwin, Eric D. Robinson, and Jeremy S. Pal. 2007. Changes in severe thunderstorm environment frequency during the 21 st century caused by anthropogenically enhanced global radiative forcing. Proceedings of the National Academy of Sciences of the United States of America. vol. 104 no. 50, pp 19719-19723

[4.] http://www.jpl.nasa.gov/news/news.php?release=2005-137

[5.] Smith, W. L., Woolf, H. M., Hayden, C. M., Wark, D. Q., and McMillin, L. M.: The TIROS-N operational vertical sounder, B.Am. Meteor. Soc., 60, 1177-1187, 1979.

[6.] Smith Sr, W. L. H. Revercomb, G. Bingham, A. Larar, H. Huang, D. Zhou, J. Li, X. Liu, and S. Kireev. Technical Note: Evolution, current capabilities, and future advance in satellite nadir viewing ultra-spectral IR sounding of the lower atmosphere. Atmos. Chem. Phys., 9, 5563-5574, 2009

[7.] Smith, W. L., Suomi, V. E., Menzel, W. P., Woolf, H. M., Sromovsky, L. A., Revercomb, H. E., Hayden, C. M., Erickson, D. N., and Mosher, F. R.: First sounding results from VAS-D, B. Am. Meteor. Soc., 62, 232236, 1981.

[8.] Smith, W. L., Revercomb, H. E., Howell, H. B., Woolf, H. M., and LaPorte, D. D.: The High Resolution Interferometer Sounder (HIS). In: Atmospheric Radiation Progress and Prospects: Beijing International Radiation Symposium, Beijing, China, 26-30 August 1986, Boston, MA, American Meteorological Society, 1987, 271-281, 1986.

[9.] Smith, W. L., Zhou, D. K., Larar, A. M., Mango, S. A., Knuteson, H. B., Revercomb, H. E., and Smith Jr.,W. L.: The NPOESS Airborne Testbed Interferometer - Remotely Sensed Surface and Atmospheric Conditions during CLAMS, J. Atmos. Sci., 62, 1118-1134, 2005.

[10.]http://airs.jpl.nasa.gov/climate/

[11.] http://www.eumetsat.int/website/home/Satellites/CurrentSatellites/Metop/index.html

[12.]Smith, W. L., Harrison, F. W., Revercomb, H. E., and Bingham, G. E.: Geostationary Fourier Transform Spectrometer (GIFTS) - The New Millennium Earth Observing-3 Mission. IRS 2000: Current problems in atmospheric radiation. Proceedings of the International Radiation Symposium, St. Petersburg, Russia, 24-29 July 2000. Hampton, VA, A. Deepak Publishing, 81-84, 2001.

[13.] Zhou, D. K., Smith Sr., W. L., Bingham, G. E., Huppi, R. J., Revercomb, H. E., Zollinger, L. J., Elwell, J. D., Larar, A. M., Liu, X., Tansock, J. J., Reisse, R. A., and Hooker, R.: Ground-based measurements with the Geosynchronous Imaging Fourier Transform Spectrometer (GIFTS) engineering demonstration unit experiment description and first results, J. Appl. Remote Sens., 1, 013528, doi:10.1117/1.2784288, 2007.

[14.] Knuteson, R. O., H. E. Revercomb, F. A. Best, N. C. Ciganovich, R. G. Dedecker, T. P. Dirkx, S. C. Ellington, W. F. Feltz, R. K. Garcia, H. B. Howell, W. L. Smith, J. F. Short, and D. C. Tobin. Atmospheric Emitted Radiance Interferometer. Part I: Instrument Design. J. Atmos. Oceanic Technol., 21, 1763-1776. 